\title{
Polyesters of 2-Pyrone-4,6-dicarboxylic Acid (PDC) as Bio-based Plastics Exhibiting Strong Adhering Properties
}

\author{
By Masakiyo HISHIDA, ${ }^{1}$ Kazuhiro SHIKINAKA, ${ }^{1,2}$ Yoshihiro KATAYAMA ${ }^{3}$ Shinya KAJITA, ${ }^{3}$ \\ Eiji MASAI, ${ }^{4}$ Masaya NAKAMURA, ${ }^{5}$ Yuichiro OTSUKA,${ }^{5}$ Seiji OHARA,${ }^{5}$ and Kiyotaka SHIGEHARA ${ }^{1,2, *}$
}

2-Pyrone-4,6-dicarboxylic acid (PDC), a chemically stable metabolic intermediate of lignin, its bis(hydroxyethyl) derivative (BHPDC) and bis(hydroxyethyl) terephthalate (BHT) were polymerized to prepare the corresponding polyesters carrying the oxyethyleneoxycarbonyl(2-pyrone-4,6-diyl)carbonyl and oxyethyleneoxy-terephthaloyl units [ $\mathrm{x}$ and $\mathrm{y}$ units, resp., $\mathrm{x}+\mathrm{y}=1$ ] by polycondensation eliminating water and/or 1,2-ethanediol molecules. The polyesters were mostly stable up to $210{ }^{\circ} \mathrm{C}$, after that the degradation of pyrone ring commenced. These polyesters exhibited strong adhering properties against metal, glass and surfaces with increasing the $\mathrm{x}$ unit content to $0.4-0.6$, such as about 50-60 MPa for SUS/polyester/SUS or Al/ polyester/Al samples, by the JIS K 6849:1994 testing method of tensile strength. As the fracturing plane was the midst of the polyester layer and at the interface, the polyester was tenaciously adhering to the metal surface.

KEY WORDS: Adhesive / Biomass / Lignin / Polyester /

Since the "carbon-neutral" sustainable chemistry became increasingly important issue ${ }^{1-8}$ the utilization of waste biomass such as lignin has long been expected to develop. ${ }^{4}$ Although biodegradable materials was thought to be one of the target products, recent social demands require the certain characteristics or properties of such materials to replace ordinary plastics with bio-based materials. Poly(hydroxyl alkanoate)s or related polyesters such as poly(L-lactate), poly(hydroxy butyrate) and poly(tetramethylene succinate) as green plastics are the commercialized examples. ${ }^{9}$ They were utilized as biodegradable films or textures. However, they have the common disadvantages such as the lack of mechanical strength (brittle or too soft) and heat-resistant properties. ${ }^{10}$ Since these disadvantages would be attributed to the lack of (pseudo-)aromatic rings in polymer chain, the introduction of (pseudo-)aromatic nuclei to the chain backbone is important for improvement in its mechanical strength and heat-resistant properties.

Thus, it is significant to prepare (pseudo-)aromatic, functional and degradable small molecules from biomass. ${ }^{11-14}$ The authors have reported the massive production of 2-pyrone-4,6dicarboxylic acid (PDC), the key intermediate chemical of lignin, by the action of transformed bacterium. ${ }^{15}$ The PDC consists of the polar pseudo-aromatic ring system and two carbonic acids, which can serve as a bifunctional monomer for polycondensation and polyaddition. In our previous work, the synthesis of the corresponding polyesters composed of oxyethyleneoxycarbonyl (2-pyran-4,6-diyl) carbonyl and oxyethyleneoxyterephthaloyl units [x and y units, resp., $\mathrm{x}+\mathrm{y}=1]$ by polycondensation was achieved. ${ }^{16}$ During the experimental procedure to prepare polyester films in order to measure the mechanical properties, the authors noticed that the polyesters sandwiched in-between of host films of polyimide (Kapton ${ }^{\circledR}$; Toray-du Pont) or aluminum adhered tenaciously to the hosts after the hot-press treatment. As no adhesive properties were found for the homopolymer of the counterpart of present polyesters, i.e., poly(oxyethyleneoxyterephthaloyl) or PET, the origin of such tenacious adhesion was considered to be derived from the pyrone repeating units.

In the present report, we describe as following three experiments; 1) the synthesis of bis(2-hydroxyethyl) 2-pyrone-4,6-dicarboxylate (BHPDC) as the new starting material for polycondensation, 2) the ternary or binary copolymerization of PDC/BHPDC/bis(2-hydroxyethyl) terephthalate (BHT) or $\mathrm{PDC} / \mathrm{BHT}$, and 3) the adhering properties of resulting polyesters with different $\mathrm{x}$ unit content against several metal surfaces.

\section{EXPERIMENTAL}

\begin{abstract}
Materials
All reagents expect for 2-pyrone-4,6-dicarboxylic acid (PDC) were obtained from Kanto Chemical Co., Wako Co., and Tokyo Kasei Co., and used without further purification. PDC was prepared from protocatechuate via the metabolic pathway of Sphingomonas paucimobilis SYK-6 as reported previously. ${ }^{15}$
\end{abstract}

Bis(2-hydroxyethyl) 2-Pyrone-4,6-dicarboxylate (BHPDC) A mixture of PDC (18.1 g, 98.2 mmol) and 1,2-ethanediol

\footnotetext{
${ }^{1}$ Graduate School of Engineering, Tokyo University of Agriculture and Technology, Koganei 184-8588, Japan

${ }^{2}$ Institute of Symbiotic Science and Technology, Tokyo University of Agriculture and Technology, Koganei 184-8588, Japan

${ }^{3}$ Graduate School of Bio-Applications and Systems Engineering, Tokyo University of Agriculture and Technology, Koganei 184-8588, Japan

${ }^{4}$ Department of Bioengineering, Nagaoka University of Technology, Nagaoka 940-2188, Japan

${ }^{5}$ Forestry and Forest Products Research Institute, Tsukuba 305-8687, Japan

*To whom correspondence should be addressed (Tel: +81-42-388-7052, Fax: +81-42-381-8175, E-mail: jun@cc.tuat.ac.jp).
} 


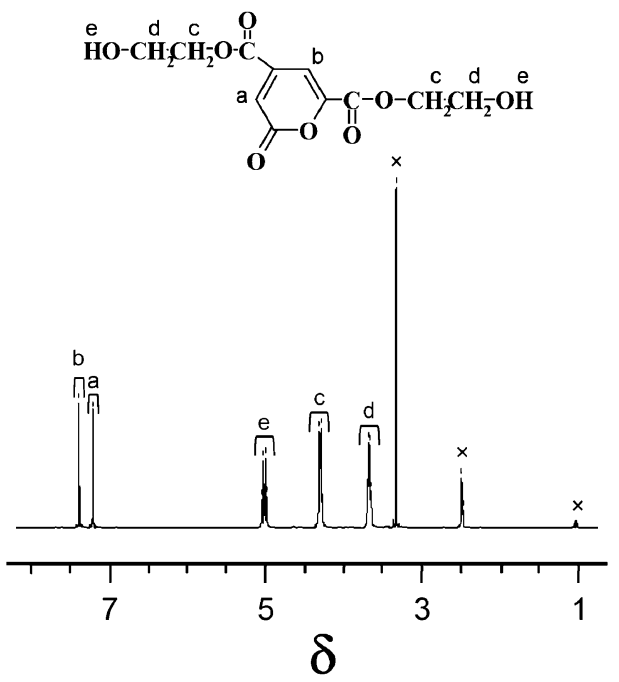

Figure 1. ${ }^{1} \mathrm{H}$ NMR spectra of BHPDC.

$(100 \mathrm{~mL}, 1.80 \mathrm{~mol})$ was preheated to $70^{\circ} \mathrm{C}$ to obtain a homogeneous solution. After the addition of conc. $\mathrm{HCl}$ $(5.0 \mathrm{~mL})$, the mixture was heated to $120^{\circ} \mathrm{C}$ for $6 \mathrm{~h}$ with gradual evacuation to $125 \mathrm{mmHg}$ in order to remove water. The mixture was allowed to cool and then stored in a freezer for $1 \mathrm{~d}$. The white powders were collected and recrystallized twice from ethanol yielding $22.2 \mathrm{~g}(83 \%)$ of desired product. $T_{\mathrm{m}}$ : $127.4{ }^{\circ} \mathrm{C}, T_{\mathrm{d}}$ (3\% weight loss): $211^{\circ} \mathrm{C}$ by thermogravimetric analysis (TG) and differential thermal analysis (DTA) at $10^{\circ} \mathrm{C} \mathrm{min}^{-1}$ under $\mathrm{N}_{2}$. IR (KBr): $v=3431,3087,2963,2883$, $1714,1636,1560,1453,1403,1376,1333,1281,1185,1119$, 1070, 1016, 1003, 950, 910, 884, 843, 781, 765, 735, 715, 618, 555, $509 \mathrm{~cm}^{-1},{ }^{1} \mathrm{H}$ NMR (DMSO- $d_{6}, 400 \mathrm{MHz}, 20{ }^{\circ} \mathrm{C}$; Figure 1): $\delta 7.39(\mathrm{~s}, 1 \mathrm{H}$, pyrone $\beta \mathrm{H}), 7.22(\mathrm{~s}, 1 \mathrm{H}$, pyrone $\delta \mathrm{H})$, 5.06 (s, 2H, - OH), 5.00 (s, 1H, -OH), $4.33 \& 4.30$ (t \& t, $2 \mathrm{H} \&$ $\left.2 \mathrm{H},-\mathrm{COOCH}_{2}-\right), 3.72 \& 3.69$ ( $\left.\& \mathrm{t}, 2 \mathrm{H} \& 2 \mathrm{H},-\mathrm{CH}_{2} \mathrm{OH}\right)$, ${ }^{13} \mathrm{C}$ NMR (DMSO- $\left.d_{6}, 100 \mathrm{MHz}, 2{ }^{\circ} \mathrm{C}\right): \delta 64\left(-\mathrm{CH}_{2} \mathrm{CH}_{2}-\right), 108$ (pyrone $\delta \mathrm{C}$ ), 122 (pyrone $\beta \mathrm{C}$ ), 144 (pyrone $\gamma \mathrm{C}$ ), 148 (pyrone $\varepsilon \mathrm{C}$ ), 158 and 159 (carboxylates), 163 (pyrone $\alpha \mathrm{C}$ ).

\section{Oligomerization}

In order to prepare the oligoesters with $\mathrm{x} \leq 0.5$ (see Scheme 1), the corresponding molar ratio mixtures of PDC and bis(2-hydroxyethyl) terephthalate (BHT) were preheated to $140{ }^{\circ} \mathrm{C}$ to obtain homogeneous molten solutions. As for the preparation of the oligoesters with $\mathrm{x}>0.5$, the similar molten solutions were prepared from the mixture of PDC, BHPDC, and BHT, where the total amount of BHPDC and BHT was stoichiometric to PDC. As shown in previous report, ${ }^{16}$ in the presence of 0.5 or $0.3 \mathrm{~mol} \%$ (with respect to total amount of monomers) of $\mathrm{Sb}_{2} \mathrm{O}_{3}$ catalyst, the further reaction at $200{ }^{\circ} \mathrm{C}$ for a given period (see Table I) solidified the charged mixtures, resulting in the corresponding oligomers with $M_{\mathrm{n}}=2.5 \times 10^{3}$ or $2 \times 10^{3}$, and $T_{\mathrm{g}}=103$ or $85^{\circ} \mathrm{C}$.

After cooling to room temperature, the solidified oligomers were crashed and ground into 400 mesh fine powders. The powdery oligomers thus obtained stoichiometrically, were

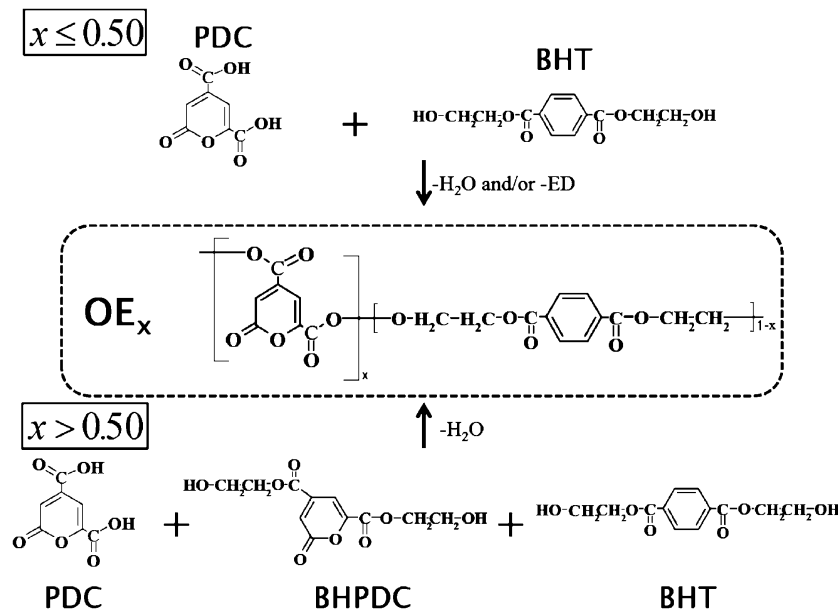

Scheme 1. Synthetic routes of $O E_{x}$.

Table I. Monomer feed ratio and oligomerization period at $200^{\circ} \mathrm{C}$

\begin{tabular}{ccccc}
\hline $\mathrm{X}$ & PDC & BHT & BHPDC & Period $/ \mathrm{min}$ \\
\hline 0.10 & 1.0 & 9.0 & 0 & 60 \\
0.20 & 2.0 & 8.0 & 0 & 60 \\
0.30 & 3.0 & 7.0 & 0 & 60 \\
0.40 & 4.0 & 6.0 & 0 & 60 \\
0.50 & 5.0 & 5.0 & 0 & 60 \\
0.60 & 5.0 & 4.0 & 1.0 & 60 \\
0.70 & 5.0 & 3.0 & 2.0 & 55 \\
0.80 & 5.0 & 2.0 & 3.0 & 50 \\
0.90 & 5.0 & 1.0 & 4.0 & 50 \\
1.00 & 5.0 & 0 & 5.0 & 45
\end{tabular}

mostly soluble (90-95\%) in THF, acetone, DMF, and DMSO. The constitution of the oligomers were confirmed by NMR spectroscopy to be essentially coincident to the feed ratio of starting materials as reported previously. ${ }^{16}$ Oligomer $(x=0.50):{ }^{13} \mathrm{C}$ NMR (DMSO- $\left.d_{6}, 100 \mathrm{MHz}, 20{ }^{\circ} \mathrm{C}\right): \delta 61-64$ (methylenes), 108 (pyrone $\delta \mathrm{C}$ ), 122 (pyrone $\beta \mathrm{C}$ ), 129 and 133 (phenylene), 142 (pyrone $\gamma \mathrm{C}$ ), 148 (pyrone $\varepsilon$ C), 158 and 159 (all carboxylate), 164 (pyrone $\alpha \mathrm{C}$ ).

\section{Polyester Film Preparation}

The oligomer powders were sandwiched between $0.05 \mathrm{~mm}$ thick aluminum foils with a $0.3 \mathrm{~mm}$-thick Teflon spacer and hot-pressed under $10 \mathrm{MPa}$ at 200,230 or $250{ }^{\circ} \mathrm{C}$ for a given period under nitrogen atmosphere. After quenched by cold nitrogen flow from liquid nitrogen overflow, the aluminum foils were removed by the action of cold $0.1 \mathrm{M} \mathrm{HCl} a q$. The resulting polyester films were rinsed with water and methanol, and dried at $60^{\circ} \mathrm{C}$ in vacuo.

\section{Sample Preparation for Measurement of Mechanical Properties}

The test pieces of glass $\left(\right.$ Pyrex $\left.^{\circledR}\right)$, glassy carbon (Tokai Carbon co.) or metal (Al, Fe, Cu, Brass, SUS304 with $6 \mathrm{~N}$ purity) for adhesion measurement had $5.0(t) \times 28.0(w) \mathrm{mm}$ edge planes and approximately $50 \mathrm{~mm}$ lengths. For the tensile 
Table II. Adhesion conditions and tensile strength by JIS K 6849-1994 testing

\begin{tabular}{rrrrrrrrr}
\hline \multirow{2}{*}{$\begin{array}{c}\text { Run } \\
\#\end{array}$} & \multirow{2}{*}{$\mathrm{x}$} & \multicolumn{3}{c}{ Adhesion } & \multicolumn{4}{c}{ Tensile strength/MPa } \\
\cline { 3 - 9 } & & $\mathrm{t} /{ }^{\circ} \mathrm{C}$ & period/min & $\mathrm{Al}$ & Brass & $\mathrm{Cu}$ & $\mathrm{Fe}$ & $\mathrm{SUS}$ \\
\hline 1 & 0.10 & 250 & 60 & 4 & 17 & 6 & - & 11 \\
2 & 0.20 & 250 & 60 & 6 & 21 & 11 & 14 & 15 \\
3 & 0.30 & 250 & 60 & 10 & 24 & 8 & 29 & 30 \\
4 & 0.40 & 250 & 60 & $* 41$ & $* 36$ & 22 & 33 & ${ }^{*} 31$ \\
5 & 0.50 & 250 & 60 & $* 44$ & 33 & 33 & 32 & ${ }^{*} 50$ \\
6 & 0.60 & 250 & 50 & $* 57$ & 22 & 23 & $* 41$ & 33 \\
7 & 0.70 & 220 & 40 & 23 & 31 & 13 & 37 & 32 \\
8 & 0.80 & 210 & 40 & 24 & 28 & 17 & 29 & 24 \\
9 & 0.90 & 200 & 40 & 14 & 13 & 8 & 16 & 20 \\
10 & 1.00 & 180 & 30 & 4 & 5 & 4 & 6 & 4 \\
\hline
\end{tabular}

-) Could not be tested due to too weak adhesion. ${ }^{*}$ ) Mixed mode fracture.

strength measurement according to JIS K 6849-1994 testing method, each edge plane surface of a coupled plates was used, after it was smoothened by using a rotating disk diamond cutter or a horizontal milling machine and then by polishing with diamond sands/oil or alumina polishing powders/oil combination to maintain the surface coarseness of $0.6-0.7 \mu \mathrm{m}$ that was confirmed from the results of surface profilometry by a Toyo Technica Dek-Tak IIA model. The plates were further washed under sonication with a series of solvents, such as, 1,2-dichloroethane, methanol, water and methanol. The thick solutions of oligomers $(5 \mathrm{mM})$ in DMF were cast both surfaces of two glass or metal plates. These plates with the oligomer layers were put together by hot-pressing at $10 \mathrm{MPa}$ and 250 $180^{\circ} \mathrm{C}$ for a given period (see Table II) under nitrogen atmosphere. During the hot-pressing, further polymerization to insoluble and infusible polyersters commenced yielding the coupled sample plates bearing $0.15 \mathrm{~mm}$-thick polyester layers for adhesion strength measurement. Similar test samples with PET (commercial reagent from Tokyo Kasei, $M_{\mathrm{n}}=2.3 \times 10^{4}$ ) layers as control were prepared by hot-pressing the 400 mesh PET powders in-between of the plates at $10 \mathrm{MPa}$ and $240^{\circ} \mathrm{C}$ for $30 \mathrm{~min}$.

\section{Measurements}

TG/DTA, and differential scanning calorimetry (DSC) measurements were carried out on a Rigaku Thermo plus TG8120 and DSC8230, respectively, under nitrogen flow, at a heating rate of $10^{\circ} \mathrm{C} \mathrm{min}^{-1}$ from $20^{\circ} \mathrm{C}$ to $1000^{\circ} \mathrm{C}$ for $\mathrm{TG}$ and from $20^{\circ} \mathrm{C}$ to $180{ }^{\circ} \mathrm{C}$ for DSC. ${ }^{13} \mathrm{C}$ NMR spectra were measured on a JEOL AL400 MHz spectrometer at $20^{\circ} \mathrm{C}$. Chemical shifts are reported in ppm downfield from $\mathrm{SiMe}_{4}$, using the solvent's residual signal as an internal reference. Infrared spectra (IR) were recorded on a JASCO FT/IR-4100 spectrometer. Number average molecular weights $\left(M_{\mathrm{n}}\right)$ of the polyesters were estimated by a JASCO 980 Gel Permeation Chromatography, calibrated by polystyrene standards. Elemental analyses of the polyesters were carried out on a Yanaco MT-5 elemental analyzer. Strain-stress curves of the polymer films were measured at $20-23{ }^{\circ} \mathrm{C}$ in an atmosphere of dry nitrogen by using a Tensilon testing machine (Auto COM/
AC-50A, TS Engineering Co.). The adhesion strength of the polyester sandwiched in-between of the glass or metal plates described above was measured by the Tensilon at $21 \pm 3{ }^{\circ} \mathrm{C}$ in atmosphere of $\mathrm{RH} \approx 60-70 \%$, according to the JIS $\mathrm{K} 6849$ 1994 (tensile strength) testing methods in which the samples were strained along the vertical direction to adhesion surface at the rate of strain $(\mathrm{d} \varepsilon / \mathrm{dt})=0.60 \mathrm{~s}^{-1}$. The maximum fracture of film samples was carried out in a similar manner. The surface coarseness of glass and metal plates was measured with a Toyo Technica surface profilometer, Dek-Tak IIA.

\section{RESULTS AND DISCUSSION}

\section{Oligomerization and Sample Preparation}

In the previous work, ${ }^{16}$ we described the preparation of oligoesters (abb.: $\mathrm{OE}_{\mathrm{x}}$ ) and polyesters (abb.: $\mathrm{PE}_{\mathrm{x}}$ ) with $\mathrm{x} \leq$ 0.50 (see Scheme 1 for the structure and definition of $\mathrm{x}$ ). The polycondensation between PDC and BHT at $200^{\circ} \mathrm{C}$ commenced rapidly with evolving either water and 1,2-ethanediol (ED) vapors to yield soluble and fusible $\mathrm{OE}_{\mathrm{x}}$ of $M_{\mathrm{n}}=2-4 \times$ $10^{3}$ within $60 \mathrm{~min}$. During the course, we found that the further post-polymerization of $\mathrm{OE}_{\mathrm{x}}$ gave insoluble and infusible $\mathrm{PE}_{\mathrm{x}}$ that tenaciously adhered to the wall of the glass reaction vessel. $\mathrm{PE}_{\mathrm{x}}$ thin films could not be prepared by hot-pressing the powdered $\mathrm{OE}_{\mathrm{x}}$ thin layers sandwiched in-between of polyimide (Kapton ${ }^{\circledR}$ ) supporting films, because the resulting $\mathrm{PE}_{\mathrm{x}}$ films could not be peeled off from Kapton ${ }^{\circledR}$ surfaces due to too strong adhesion. Changing the supporting materials to metal or glassy carbon films gave same results, and therefore, we decided to prepare $\mathrm{PE}_{\mathrm{x}}$ films by using aluminum foils that could be removed afterwards by the action of diluted aqueous acid. Thus as in consequence, we encountered the anomalous adhering properties of simple structured ester-type polymers.

In order to know the relation between the constitution and the adhering properties, it is better to examine $\mathrm{PE}_{\mathrm{x}}$ with wide $\mathrm{x}$ values. By the polycondensation between PDC and BHT with eliminating either water and/or $\mathrm{ED}$, the $\mathrm{x}$ value cannot exceed 0.5. Addition of BHPDC to the PDC+BHT mixture was necessary to prepare $\mathrm{OE}_{\mathrm{x}}$ with $\mathrm{x}>0.5$ as shown in Scheme 1 and Table I.

Because the $\mathrm{PE}_{\mathrm{x}}$ samples were insoluble and infusible, the corresponding $\mathrm{OE}_{\mathrm{x}}$ (obtained as summarized in Table I) films were thrown onto the surfaces of a couple of metal plates from their DMF thick solutions, and the plates were put together by hot-pressing at $10 \mathrm{MPa}$ and $250-180^{\circ} \mathrm{C}$ for a given period (see Table II).

During the hot-pressing the post-polymerization commenced to yield the $\mathrm{PE}_{\mathrm{x}}$ layers and the adhesion of metal plates was completed.

The adhesion test samples of PET (commercial reagent from Tokyo Kasei, $M_{\mathrm{n}}=2.3 \times 10^{4}$ ) were similarly prepared by hotpressing the 400 mesh powders at $10 \mathrm{MPa}$ and $240{ }^{\circ} \mathrm{C}$ for $30 \mathrm{~min}$, for instance. However, after the cooling of the test samples by soaking them into liquid nitrogen or by standing them in ambient atmosphere, they were instantaneously separated into two metal pieces and a thin film of PET in 
both cases. Attempts to optimize the condition by changing the parameter (temperature and period) of hot-pressing and the method of quenching or annealing failed due to rapid spherulite formation. Thus, no adhesion test was possible for PET.

\section{Adhesion Strength}

Because the post-polymerization of $\mathrm{OE}_{\mathrm{x}}$ into $\mathrm{PE}_{\mathrm{x}}$ was necessary to complete adhesion, the conditions of hot-pressing (i.e., temperature, period and pressure) was considered to be an important factor. As the adhesion strength became constant when the applied pressure during the hot-pressing exceeded $7 \mathrm{MPa}$, it was settled to $10 \mathrm{MPa}$ throughout the experiments. The influence of the temperature and the period on the adhesion strength was delicate. When the hot-pressing treatment was carried out at relatively low temperature such as $180-200^{\circ} \mathrm{C}$, longer period was necessary in order to complete the postpolymerization. On the other hand, the hot-pressing at more elevated temperature such as $250{ }^{\circ} \mathrm{C}$ commenced the postpolymerization more rapidly, and however, the certain change to concentrated color also observed. $\mathrm{OE}_{\mathrm{x}}$ or $\mathrm{PE}_{\mathrm{x}}$ prepared at relatively low temperature exhibited pale yellow color due to the near UV $\left(\lambda_{\max }=321 \mathrm{~nm}\right)$ absorption band of PDC $\pi$ system, ${ }^{17}$ those obtained at the elevated temperature had deep brown to black color. Because the degradation of 2-pyrone ring starts at about $220^{\circ} \mathrm{C},{ }^{16}$ such color change tendency was more outstanding in the $\mathrm{PE}_{\mathrm{x}}$ samples with larger $\mathrm{x}$ values. As for the $\mathrm{PE}_{0.10}-\mathrm{PE}_{0.50}$ samples prepared by the prolonged post-polymerization at $200^{\circ} \mathrm{C}$ of which temperature does not cause degradation of 2-pyrone ring, it was reported previously that the onset of weight-loss in the thermal gravimetry shifted to lower temperature side with increasing $\mathrm{x} .{ }^{15}$ This feature is extrapolatively confirmed for the $\mathrm{PE}_{\mathrm{x}}$ samples with $\mathrm{x}>0.5$ obtained by the present improved synthetic procedure, and the results are shown in Figure 2. One can notice that $\mathrm{PE}_{1.0}$ started to degrade at the lowest temperature of about $220^{\circ} \mathrm{C}$.

Along with the progress of the post-polymerization from $\mathrm{OE}_{\mathrm{x}}$ to $\mathrm{PE}_{\mathrm{x}}$, the samples turned to infusible hard plastics. At the same time the color change and partial deterioration occurred depending on the content of 2-pyrone repeating unit, and the temperature or period of post-polymerization. In order to know the optimum conditions that give satisfactory tensile strength of adhesion of SUS plates, the reaction period for

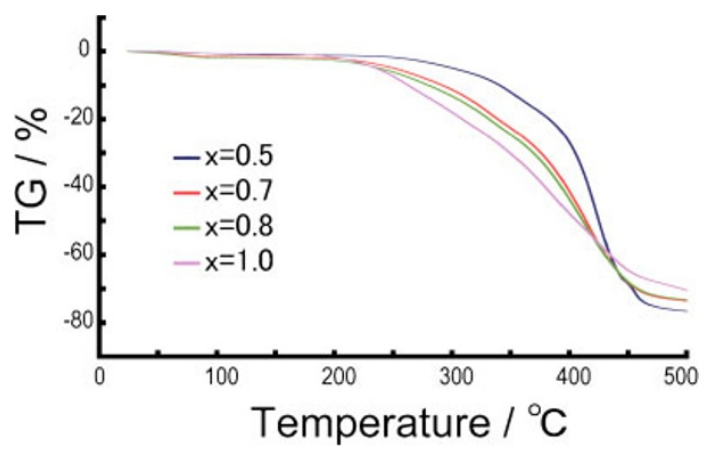

Figure 2. TG curves of $P E_{x}$ at a heating rate of $10^{\circ} \mathrm{Cmin}^{-1}$ under $\mathrm{N}_{2}$.
$\mathrm{OE}_{0.50}$ at 200,230 and $250^{\circ} \mathrm{C}$ was changed from 30 to $240 \mathrm{~min}$ as illustrated in Figure 3. Similarly, the maximum fracture of the $\mathrm{PE}_{0.50}$ film samples prepared separately by the postpolymerization of thin film-shape $\mathrm{OE}_{0.50}$ (see Experimental) at 3 different temperatures was measured and the results were also shown in Figure 3. From every strain-stress curve in the tensile strength measurement of adhesion and in the film fracture measurement, no elongation was noticed in the present $\mathrm{PE}_{\mathrm{x}}$ samples.

At $200{ }^{\circ} \mathrm{C}$, the $\mathrm{PE}_{0.50}$ film maintained its original pale yellow color even after $240 \mathrm{~min}$ post-polymerization. The film post-polymerized for $180 \mathrm{~min}$ gave the largest tensile strength of fracture. However, the tensile strength of adhesion was relatively low level in all polymerization periods. In every case the breakdown of adhesion was found to be the interfacial mode, i.e., the SUS test pieces were separated at the interface of $\mathrm{PE}_{0.50}$ layer and SUS surface. Because the post-polymerization at $200{ }^{\circ} \mathrm{C}$ for $180 \mathrm{~min}$, for instance, was enough to prepare mechanically strong $\mathrm{PE}_{0.50}$ film, the reason of low tensile strength of adhesion was due to insufficient interfacial interaction between the $\mathrm{PE}_{0.50}$ layer and the SUS surface.

When the temperature was elevated to $230^{\circ} \mathrm{C}$, the postpolymerization commenced more rapidly. ${ }^{15}$ But the color change to brown color was observed, and the maximum tensile strength of the film fracture was decreased to $62 \mathrm{MPa}(90 \mathrm{~min})$. Also note that the maximum tensile strength of the film fracture decreased to smaller value after $90 \mathrm{~min}$ due to partial deterioration. On the other hand, the tensile strength of adhesion was improved than that performed at $200^{\circ} \mathrm{C}$. The maximum value was found in the 120 min-reacted sample, i.e., $44 \mathrm{MPa}$. Interestingly, only in the case of the sample reacted for 120 min the breakdown of adhesion was the mixed mode, i.e., the SUS test pieces are separated both at the midst of $\mathrm{PE}_{0.50}$ layer and at the interface of SUS and $\mathrm{PE}_{0.50}$ layer, although it was the interfacial mode in other cases.

At $250{ }^{\circ} \mathrm{C}$, the color change to dark brown color was more significant. The counter effect of rapid post-polymerization and deterioration gave the maximum tensile strength of the film at the reaction period of $60 \mathrm{~min}$ which is relatively early stage of the post-polymerization. Although the tensile strength of the film fracture in this temperature series was not large, the adhesion test sample prepared at $250{ }^{\circ} \mathrm{C}$ for $60 \mathrm{~min}$ exhibited the largest tensile strength of adhesion among not only those prepared at this temperature but also at 230 and $200{ }^{\circ} \mathrm{C}$. Except for the sample prepared by the post-polymerization for $30 \mathrm{~min}$, the breakdown of adhesion in the $250{ }^{\circ} \mathrm{C}$ series was the mixed mode which indicates that the strong interfacial interaction with the SUS surface and relatively weakened mechanical strength of $\mathrm{PE}_{0.50}$ layer due to partial deterioration. At the elevated temperatures such as $250^{\circ} \mathrm{C}$, metal hydroxides or metal oxides on the metal surface and 2-pyrone ring can form ring-opening addition product (Scheme 2-1) as pointed out previously. ${ }^{15}$ The ring-opening as shown in Scheme 2-1 by hydroxyl ions was predicted in polyamides containing fivemembered lactone unit, ${ }^{18}$ and the structural transformation of 2-pyron ring at $200-250{ }^{\circ} \mathrm{C}$ was also expected. ${ }^{19}$ Such covalent 

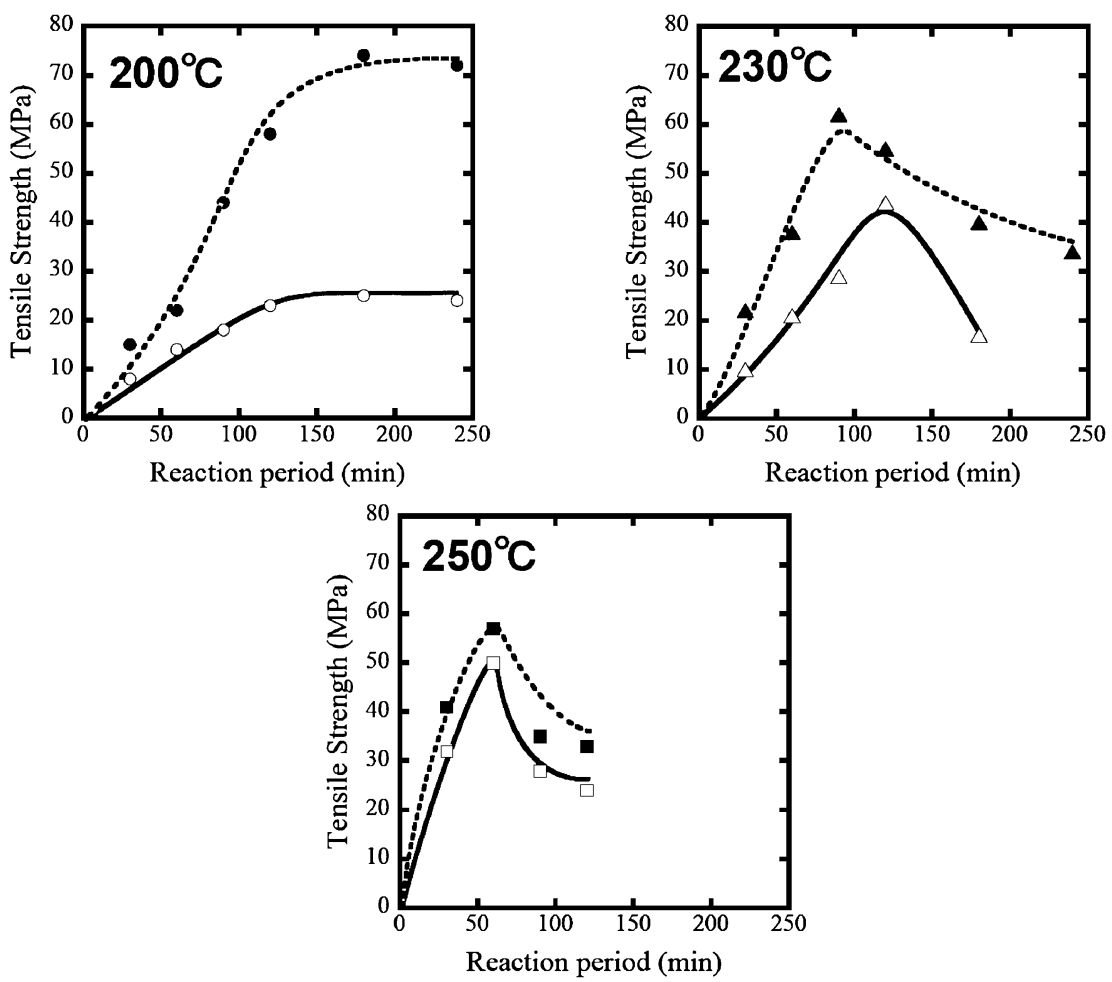

Figure 3. Relation between the reaction period for $\mathrm{OE}_{0.50}$ and the tensile strength of adhesion of SUS plates (open symbols), and between the postpolymerization period for $\mathrm{OE}_{0.50}$ films and the maximum fracture of resulting $\mathrm{PE}_{0.50}$ films (closed symbols). Reaction temperature, ${ }^{\circ} \mathrm{C}: 200$ ( $\bigcirc,{ }^{\circ}$ ), 230 $(\triangle, \mathbf{\Delta})$ and $250(\square, \square)$

bonding formation as well as the chelating coordination of three carbonyl groups in one repeating unit is considered to be the origin of strong adhesion.

From the temperature-constant $\left(\right.$ at $250{ }^{\circ} \mathrm{C}$ ) time-scan thermal gravimetry of $\mathrm{PE}_{0.50}$ that was obtained by the postpolymerization at $200{ }^{\circ} \mathrm{C}$, the weight loss in the nitrogen atmosphere was merely $1-3 \mathrm{wt} \%$ after $60 \mathrm{~min}$. Frequent mainchain scission was not likely to occur, as no soluble part corresponding to oligomers was found by solvent extraction with aliphatic alcohols, acetone, THF, DMF and DMSO after heating at $250{ }^{\circ} \mathrm{C}$ for $60 \mathrm{~min}$. Unfortunately, the comparison of FT/IR spectra before and after the heating treatment did not give any notable difference except for the deeper baseline in the heated sample due to dark color. One of the plausible pathways of deterioration by heating was represented in Scheme 2-2, where the ring-opening addition of water molecules (by-product of polycondensation) was the first event, followed by the enol-keto rearrangement and the $\mathrm{CO}_{2}$ and/or $\mathrm{CO}$ elimination from the resulting hydroxycarbonyl and/or $\alpha$ ketocarboxylate groups.

In such a way, the optimum temperature and period for adhesion of several metal plates was determined and listed in Table II. It was mostly $250{ }^{\circ} \mathrm{C}$ and $60 \mathrm{~min}$, when $\mathrm{x}$ was smaller than 0.50 . With increasing $\mathrm{x}$, the adhesion strength in every metal plate was enhanced before that reached $0.40-0.60$, indicating that the pyrone repeating unit plays an important role on the generation of adhesion properties. During the course, the breakdown mode was changed from "interfacial" to "mixed" (see Table II), except for the case of the $\mathrm{Cu}$ plate adhesion. The adhesion strength reached to the maximum values of about $30-60 \mathrm{MPa}$ at $\mathrm{x}=0.40-0.60$, being larger than that of the conventional hot-melt type polyester adhesives (i.e., $\sim 10 \mathrm{MPa}$ of lap shear $\operatorname{stress}^{20}$ ) and Aron Alpha ${ }^{\circledR}$ (i.e., $\sim 27 \mathrm{MPa}$ of tensile stress). Beyond these $\mathrm{x}$ values, the adhesion strength decreased and the breakdown mode was again turned to "interfacial." Lower temperature and shorter period was applied to the $\mathrm{PE}_{\mathrm{x}}$ sample with $\mathrm{x}>0.40-0.60$ in order to avoid excessive deterioration. From these results, at high $\mathrm{x}$ values, the strength reduction of $\mathrm{PE}_{\mathrm{x}}$, due to the excessive deterioration should be occurred the decrease of adhesion strength. Although such conditions were good enough to commence the post-polymerization, it was not sufficient to promote concrete interfacial interactions.

Among 5 kind of metals, the adhesion strength was rather small in the case of $\mathrm{Cu}$ plates. Metal hydroxides or oxides are easier to be formed in other 4 metal surfaces, such properties are anticipated to affect the strength of the interfacial interaction.

Experiments for the adhesion test of glass plates and glassy carbon plates ended incomplete, because the breakdown of plates occurred before the fracturing of adhesion. It was unavoidable to prepare a notch or a pin-hole in order to hold the sample plates by the tensilatometer, the cracking was formed from the notch or the pin-hole as shown in Figure 4, for instance. About $30 \mathrm{MPa}$ and $38 \mathrm{MPa}$ for the glass and glassy carbon plate experiments, respectively, were recorded before the breakdown of the substrates. 


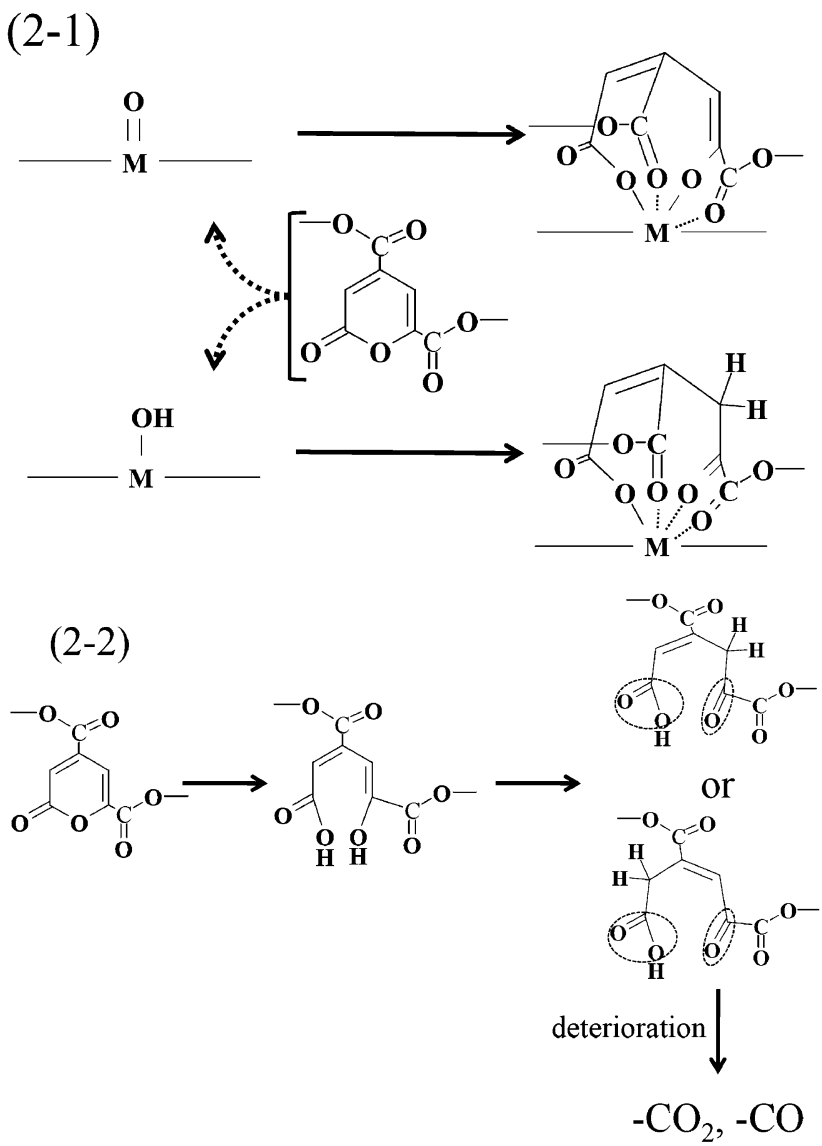

Scheme 2. (2-1): Anticipated reaction of adhesion interface and degradation pathway of PDC nuclei in $\mathrm{PE}_{\mathrm{x}}$. (2-2): Anticipated degradation pathway of PDC nuclei in the polymers by heating.

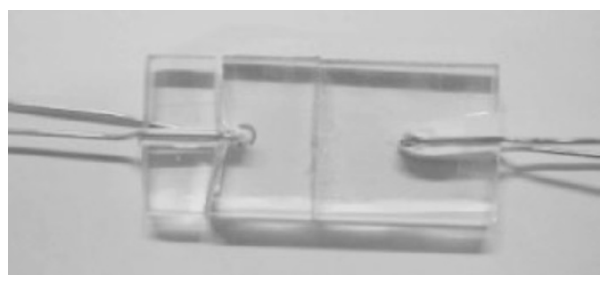

Figure 4. Glass plates adhered by the post-polymerization of $\mathrm{OE}_{0.50}$ layer at $250^{\circ} \mathrm{C}, 60 \mathrm{~min}$ and fractured after the tensilatometry.

\section{CONCLUSION}

Anomalous adhesion properties of bio-based polyesters as high as about 30-60 MPa against several metals were reported. The creation of chemical bonding at the interface of the $\mathrm{PE}_{\mathrm{x}}$ layer and the metal surface by the ring-opening addition reaction was anticipated to be the origin of the strong adhering.

Acknowledgment. This work was supported by a Grant-inAid for Scientific Research from the Ministry of Education, Culture, Sports, Science and Technology, Japan (\#18208028) and a grant from the Ministry of Agriculture, Forestry and Fisheries of Japan (Rural Biomass Research Project, BMD1310).

Received: November 14, 2008 Accepted: December 26, 2008 Published: February 18, 2009

\section{REFERENCES}

1. "Biopolymers," A. Steinbuchel, Y. Doi, and M. Hofrichter, Ed. Vol. 3, Wiley-VCH, Weinheim, 2002.

2. E. T. H. Vink, K. R. Rabago, D. A. Glassner, and P. R. Gruber, Polym. Degrad. Stab., 80, 403 (2003).

3. "Biorefineries-Industrial Processes and Products," B. Kamm, P. R. Gruber, and M. Kamm, Ed., Wiley-VCH, Weinheim, 2006.

4. A. J. Ragauskas, C. K. Williams, B. H. Davison, G. Britovsek, J. Cairney, C. A. Eckert, W. J. Frederick, Jr., J. P. Hallett, D. J. Leak, C. L. Liotta, J. R. Mielenz, R. Murphy, R. Templer, and T. Tschaplinski, Science, 311, 484 (2006).

5. Y. Nishio, Adv. Polym. Sci., 205, 97 (2006).

6. S.-i. Hirota, T. Sato, Y. Tominaga, S. Asai, and M. Sumita, Polymer, 47, 3954 (2006).

7. B. Kamm, Angew. Chem., Int. Ed., 46, 5056 (2007).

8. J. N. Chheda, G. W. Huber, and J. A. Dumesic, Angew. Chem., Int. Ed., 46, 7164 (2007).

9. D. Riggle, BioCycle, 39, 64 (1998).

10. T. Kaneko, T. H. Thi, D. J. Shi, and M. Akashi, Nat. Mater., 5, 966 (2006).

11. M. Funaoka, Polym. Int., 47, 277 (1998).

12. Y. Román-Leshkov, C. J. Barrett, Z. Y. Liu, and J. A. Dumesic, Nature, 447, 982 (2007).

13. A. Corma, S. Iborra, and A. Velty, Chem. Rev., 107, 2411 (2007).

14. S. R. Boethling, E. Sommer, and D. DiFiore, Chem. Rev., 107, 2207 (2007).

15. Y. Otsuka, M. Nakamura, K. Shigehara, K. Sugimura, E. Masai, S. Ohara, and Y. Katayama, Appl. Microbiol. Biotechnol., 71, 608 (2006).

16. T. Michinobu, M. Hishida, M. Sato, Y. Katayama, K. Noguchi, E. Masai, M. Nakamura, Y. Otsuka, S. Ohara, and K. Shigehara, Polym. J., 40, 68 (2008).

17. T. Michinobu, M. Bito, Y. Yamada, Y. Katayama, K. Noguchi, E. Masai, M. Nakamura, S. Ohara, and K. Shigehara, Bull. Chem. Soc. Jpn., 80, 2436 (2007).

18. T. Kimura, T. Kimura, and M. Minabe, Koubunshi Ronbunshu, 55, 677 (1998).

19. T. Kimura, H. Miyata, A. Tanaka, and S. Nishikawa, Koubunshi Ronbunshu, 58, 86 (2001)

20. X. Chen, H. Zhong, L. Jia, J. Ling, R. Tang, J. Qiao, and Z. Zhang, J. Appl. Polym. Sci., 81, 2696 (2001). 